\title{
Microparticles in patients undergoing transcatheter aortic valve implantation (TAVI)
}

\author{
Christian Jung ${ }^{1,3} \cdot$ Michael Lichtenauer ${ }^{2,3} \cdot$ Hans-Reiner Figulla ${ }^{3}$. \\ Bernhard Wernly ${ }^{2}$ Bjoern Goebel ${ }^{3} \cdot$ Martin Foerster $^{3} \cdot$ Christoph Edlinger $^{2}$. \\ Alexander Lauten ${ }^{3,4}$
}

Received: 28 March 2016 / Accepted: 29 July 2016 / Published online: 3 August 2016

(C) The Author(s) 2016. This article is published with open access at Springerlink.com

\begin{abstract}
Degenerative aortic stenosis (AS) is the most frequent form of acquired valvular heart disease. AS is known to entail endothelial dysfunction caused by increased mechanical shear stress leading to elevated circulatory levels of microparticles. Endothelial and platelet microparticles (EMP and PMP) are small vesicles that originate from activated cells and thrombocytes. We sought to evaluate whether transcatheter aortic valve implantation (TAVI) procedure would elicit effects on circulating EMP and PMP. 92 patients undergoing TAVI procedure for severe AS were included in this study. Samples were obtained at each visit before TAVI, 1 week post-procedure and at 1,3 and after 6 months after TAVI and were evaluated using flow cytometry. A 12 month clinical follow-up was also performed. CD62E + EMP concentration before TAVI was $21.11 \%( \pm 6.6 \% \mathrm{SD})$ and declined to $20.99 \%( \pm 6.8 \%$
\end{abstract}

C. Jung and M. Lichtenauer contributed equally.

Electronic supplementary material The online version of this article (doi:10.1007/s00380-016-0885-z) contains supplementary material, which is available to authorized users.

Christian Jung

christian.jung@med.uni-duesseldorf.de

1 Division of Cardiology, Pulmonology, and Vascular Medicine, Medical Faculty, University Hospital Düsseldorf, University Duesseldorf, Moorenstrasse 5, 40225 Düsseldorf, Germany

2 Department of Cardiology, Clinic of Internal Medicine II, Paracelsus Medical University of Salzburg, Salzburg, Austria

3 Department of Cardiology, Clinic of Internal Medicine I, Universitätsherzzentrum Thüringen, Friedrich Schiller University Jena, Jena, Germany

4 Department of Cardiology, Charité-Universitaetsmedizin Berlin, Berlin, Germany
$\mathrm{SD})$ after 1 week, to $16.63 \%( \pm 5.4 \% \mathrm{SD}, p<0.0001)$ after 1 month, to $17.08 \%( \pm 4.6 \% \mathrm{SD}, p<0.0001)$ after 3 months and to $15.94 \%( \pm 5.4 \% \mathrm{SD}, p<0.0001)$ after 6 months. CD31+/CD42b-, CD31+/Annexin+/- EMP remained unchanged. CD31+/CD41b+ PMP evidenced a slight, but statistically significant increase after TAVI and remained elevated during the entire follow-up. Apart from a procedure-related improvement in echocardiographic parameters, TAVI procedure led also to a decline in CD62E+ EMP. The reduction in pressure gradients with less hemodynamic shear stress seems also to have beneficially affected endothelial homeostasis.

Keywords Endothelial microparticles · Platelet microparticles · Endothelial dysfunction · TAVI . Aortic stenosis

\section{Introduction}

Degenerative aortic stenosis (AS) is the most frequent form of acquired valvular heart disease worldwide and its prevalence is expected to further increase within the aging population. Although the majority of patients have only mild valve disease, about $5 \%$ develop severe AS [1-3]. Morbidity and mortality rates are considerably high among patients not undergoing valve replacement. Once symptoms occur in these patients, the mortality rate is approximately $50 \%$ over the next 3 years [4].

Pathophysiology of aortic stenosis can be characterized by multiple steps: inflammation, fibrosis and finally calcification. It is not completely understood whether inflammation in aortic stenosis is a response to tissue injury or if aortic stenosis might be primarily an inflammatory disease. From the literature we know that pro-inflammatory 
markers such as Tumor necrosis factor-alpha (TNF-alpha), receptor activator of nuclear factor-kappa $\mathrm{B}(\mathrm{NF}-\kappa \mathrm{B})$ ligand (RANKL) and Interleukin-6 (IL-6) are associated with aortic stenosis [5-8]. Also elevated plasma levels of lowdensity lipoprotein cholesterol were associated with an augmented aortic valve calcium deposition and a higher incidence of aortic stenosis [9].

As there is no medical treatment for aortic stenosis besides vasodilators and diuretics for acute decompensation, the mainstay of treatment for aortic stenosis is still surgical or interventional aortic valve replacement $[6,10]$. Ongoing inflammation in the circulatory system and increased shear stress has also been associated with endothelial dysfunction [11, 12]. Over the last few years, microparticles have come more and more into the focus of clinical scientists as they can serve as parameters to determine and monitor vascular dysfunction in several disease conditions [12-16].

Microparticles are defined as small phospholipid vesicles without a nucleus that are released from different cells, platelets, erythrocytes, leukocytes and endothelial cells [17-19]. Endothelial cell microparticles (EMP) can be identified by antigens expressed by mature endothelial cells such as CD31 [20]. EMP concentrations are known to reflect endothelial dysfunction as there are strong associations between increased circulating EMPs and both structural and functional abnormalities [21, 22]. Microparticles derived from platelets (PMP) are identified by the expression of platelet markers such as CD41 or CD61 [23]. High levels of PMPs are known to be strongly associated with thrombotic complications [24]. Horn et al. have recently shown that EMPs decrease 3 months after transcatheter aortic valve implantation (TAVI), reflecting improved endothelial function and wall shear stress [25].

The main focus of our study was to further extend our knowledge about microparticles in AS and patients undergoing TAVI. We sought to evaluate whether TAVI procedure could lead to an alteration or possible decrease in circulating levels of both endothelial and platelet microparticles epitomizing an improvement in vascular integrity and function after 1, 3 and 6 months indicating a possible longterm beneficial effect of interventional aortic valve replacement on overall endothelial function.

\section{Methods}

The study protocol was approved by the Ethics Committee of the Friedrich-Schiller-University, Jena, Germany. The study was conducted according to the principles of the Declaration of Helsinki and Good Clinical Practice and informed consent was obtained from all patients before being enrolled.

\section{Study protocol}

A total of 92 patients suffering from symptomatic severe AS admitted to our clinic for TAVI were enrolled in this study between November 2011 and February 2014. The diagnosis of severe AS was defined according to the guidelines of the European Society of Cardiology. Mean and peak pressure gradients (MPG and PPG), maximum velocity $\left(V_{\max }\right)$ and aortic valve area were assessed by transthoracic echocardiography by experienced sonographers in our echo lab. All patients underwent pre-interventional screening with ECG, laboratory parameters, transthoracic and transesophageal echocardiography and coronary angiography. The obtained results were discussed in the interdisciplinary heart team. Patients that were considered not eligible for operative aortic valve replacement were planned for TAVI procedure.

TAVI procedure was performed via transfemoral access in 77 patients and via a transapical approach in 15 patients. In patients undergoing transfemoral TAVI, a 14-21 French delivery sheath was inserted in the femoral artery, depending on the size and type of TAVI-device. In patients without a permanent pacemaker, a temporary transcutaneous pacemaker was placed via transjugular access for periprocedural rapid pacing. A balloon valvuloplasty was performed during rapid pacing. Subsequently, implantation of the valve prosthesis (Edwards Sapien XT, $n=64$; Corevalve, $n=11$; JenaValve, $n=13$; SJM Portico, $n=4$ ) was performed. Using a closure device (Proglide; Abbott USA) the artery access was closed. For the transapical approach, an anterolateral mini-thoracotomy was performed to obtain optimal access to the apex of the left ventricle followed by pericardiotomy. The left ventricular apex was punctured with a standard access needle and an access wire was inserted. Then, a 12 French sheath was placed in the apex for ventricular access. Next, a balloon valvuloplasty was performed during rapid pacing. The valve was then introduced over the sheath and placed in the right position under angiographic control. The pharmacological regimen after TAVI in our clinic comprised of $100 \mathrm{mg}$ of acetylsalicylic acid and $75 \mathrm{mg}$ of clopidogrel for 3 months which was followed by a monotherapy of $100 \mathrm{mg}$ of acetylsalicylic acid.

Plasma samples were obtained from all enrolled patients on the day of the procedure and 1 week post-procedure and at each of the follow-up visits after 1, 3 and 6 months.

\section{Flow cytometry}

Microparticles in the collected blood samples were stained with antibodies against CD31, CD42b, CD62E and Annexin to analyze circulatory levels of $\mathrm{CD} 31+$ / Annexin+, CD31+/Annexin-, microparticles using flow cytometry. EMP were defined as CD $31+/ \mathrm{CD} 42 \mathrm{~b}-$ and $\mathrm{PMP}$ as $\mathrm{CD} 31+/ \mathrm{CD} 42 \mathrm{~b}+$. 
According to previous studies [13, 18, 26], samples were centrifuged for $10 \mathrm{~min}$ at $2000 \mathrm{~g}$. For the preparation of platelet-poor plasma, the plasmatic supernatant was obtained without disturbing the buffy coat. Fifty microliters of platelet-poor plasma was incubated for $20 \mathrm{~min}$ with labeled antibodies: $4 \mu \mathrm{l}$ of anti-CD31-PE (BD Pharmigen, USA), anti-CD62-FITC (Ancell Corporation, USA), antiCD42b-Cy5 (BD Pharmigen, USA) and anti-Annexin-VAPC (BD Pharmigen, USA) or matching isotype controls (all from BD Pharmigen, USA). In the next step, samples were then diluted with $1 \mathrm{ml}$ of phosphate-buffered saline (PBS) and analyzed on a flow cytometer (FACS Calibur, BD Biosciences, USA).

To determine the size of the acquired events, size calibration beads were added to the samples (Molecular Probes, Invitrogen, USA). MP were defined as particles that were smaller than $1.5 \mu \mathrm{m}$. MP were expressed as percentage of events in the relevant gate. The obtained data were processed using CellQuest Pro software (BD Biosciences, USA).

\section{Statistical analysis}

Statistical analysis was performed using GraphPad Prism software (GraphPad Software, La Jolla, USA). All data are given as mean \pm standard deviation (SD) or median with interquartile range (IQR). The Wilcoxon's matched pairs and the paired $t$-test were utilized to calculate significances between the groups. $p$ values $<0.05$ were considered statistically significant. Bonferroni-Holm correction was used to adjust $p$ values for multiple testing. * indicates a $p$ of $<0.05$, ** a $p$ of $<0.01$ and $* * *$ a $p$ of $<0.001$.

\section{Results}

The characteristics of the study population are presented in Table 1.92 patients with a mean age of $80.0 \pm 7.13$ years were included in the study and were followed-up over a period of 6 month after TAVI with periodical blood withdrawals for EMP and PMP analysis. At 12 month postTAVI, a clinical follow-up was performed. Four different valve types were used (Edwards Sapien XT $n=64$, Corevalve $n=11$, JenaValve $n=13$, SJM Portico $n=4$ ). Follow-up time points with measurement of microparticles were prior to TAVI and 1 week post-TAVI and at 1 , 3 and 6 months after TAVI (see Fig. 1). Mean EuroScore was $23.1 \pm 14.5$. TAVI procedure was performed via transfemoral access in 77 patients, whereas in 15 patients the valve was implanted via a transapical approach. None of the patients died within the 30 days after TAVI, though, five patients died within the 12 months follow-up period (mortality rate $5.4 \%$ ). Complication rates defined using VARC-2 criteria are also stated in Table 1 [27]. In total, six patients evidenced neurological deficit after TAVI (stroke $n=3$, TIA $n=3$ ). Acute kidney injury according to VARC-2 criteria occurred in two patients (stage $1 n=1$, stage $2 n=1$ ). Minor bleeding complications (vascular site hematoma, transfusion of $<2$ red blood cell concentrates) according to VARC-2 criteria occurred in 16 patients $(17.4 \%)$, major bleeding complications (transfusion of $\geq 2$ red blood cell concentrates) in 24 patients $(26.1 \%)$ and relevant vascular access-related complications (dissection, pseudoaneurysm) in 8 patients $(8.7 \%)$. Implantation of a permanent pacemaker was necessary within $72 \mathrm{~h}$ in 5 patients $(5.4 \%)$. Permanent pacemaker implantation was performed in $13 \%$ of patients after TAVI procedure, these data are comparable with previously published results [28]. Conversion to open surgery due valve malpositioning was necessary in 1 patient. Forty patients $(43.5 \%)$ were free of post-procedural aortic insufficiency, grade $0-1$ (trace) aortic insufficiency was present in 21 patients $(22.8 \%)$, grade 1 in 29 patients (31.5\%) and $\geq$ grade 2 only in 1 patient $(1.1 \%)$. Clinical and functional results after TAVI procedure were good as shown by significantly reduced $V_{\max }$, MPG and PPG $(p<0.001)$. Also a slight improvement in ejection fraction was documented during follow-up, from $55.9 \%( \pm 18.4 \mathrm{SD})$ before TAVI to $62.6 \%( \pm 14.3 \mathrm{SD})$ after 6 months $(p<0.01)$. A procedurerelated drop in hemoglobin levels from $7.6 \mathrm{mmol} / \mathrm{l}( \pm 1.1$ $\mathrm{SD})$ to $6.69( \pm 1.0 \mathrm{SD}, p<0.001)$ and an increase of CRP from $13.9 \mathrm{mg} / \mathrm{l}( \pm 29.3 \mathrm{SD})$ to $42.5 \mathrm{mg} / \mathrm{l}( \pm 29.8, p<0.001)$ was also over served. However, at later visits levels returned to those seen before TAVI procedure. It is of note that creatinine levels did not increase significantly immediately following TAVI procedure, however, during the follow-up a rise in creatinine was found (see Table $2, p<0.01$ ).

Plasma samples were obtained at each study visit and were analyzed for EMP and PMP. EMP were defined as CD62E + and CD31+/CD42- and PMP as $\mathrm{CD} 31+\mathrm{CD} 42 \mathrm{~b}+$. Pre TAVI levels of $\mathrm{CD} 31+\mathrm{CD} 42 \mathrm{~b}-$ EMP correlated with $V_{\max }(r=0.258, p=0.016)$, MPG $(0.301, p=0.004)$ and PPG $(0.230, p=0.032)$, see Fig. 2 . No significant correlation was found for CD31+CD42bEMP with aortic valve area (AVA). A correlation analysis of all EMP and PMP populations with parameters of aortic valve function is shown in supplementary Table 1.

CD62E + EMP concentration before TAVI was $21.11 \%$ $( \pm 6.6 \% \mathrm{SD})$ and declined to $20.99 \%( \pm 6.8 \% \mathrm{SD})$ after 1 week, to $16.63 \%( \pm 5.4 \% \mathrm{SD}, p<0.0001)$ after 1 month, to $17.08 \%( \pm 4.6 \% \mathrm{SD}, p<0.0001)$ after 3 months and to $15.94 \%( \pm 5.4 \% \mathrm{SD}, p<0.0001)$ after 6 months (see Fig. 3). No statistically significant differences were found for CD31+/CD42- EMP: pre TAVI $0.57 \%( \pm 0.45 \% \mathrm{SD})$, 1 week $0.65 \%( \pm 0.45 \%$ SD $), 1$ month $0.66 \%( \pm 0.65 \%$ SD), 3 months $0.69 \%( \pm 0.76 \% \mathrm{SD})$ and 6 months $0.62 \%$ $( \pm 0.55 \% \mathrm{SD})$. 
Table 1 Patient characteristics of the study cohort before TAVI procedure

\begin{tabular}{|c|c|}
\hline Demographic parameters & SD \\
\hline$n$ & 92 \\
\hline Age (years) & $80.0 \pm 7.13$ \\
\hline Height (cm) & $163.4 \pm 9.3$ \\
\hline Weight $(\mathrm{kg})$ & $76.9 \pm 13.3$ \\
\hline NYHA stage & $2.75 \pm 1.38$ \\
\hline \multirow[t]{2}{*}{ Euroscore } & $23.1 \pm 14.5$ \\
\hline & Total $(\%)$ \\
\hline Diabetes & $42(45.6 \%)$ \\
\hline Arterial hypertension & $82(89.1 \%)$ \\
\hline Coronary artery disease & $68(73.9 \%)$ \\
\hline One vessel disease & $21(22.8 \%)$ \\
\hline Two vessel disease & $9(9.8 \%)$ \\
\hline Three vessel disease & $19(20.6 \%)$ \\
\hline Myocardial infarction & $12(13.0 \%)$ \\
\hline Atrial fibrillation & $5(5.4 \%)$ \\
\hline Stroke & $9(9.8 \%)$ \\
\hline Peripheral artery disease & $20(21.7 \%)$ \\
\hline COPD & $20(21.7 \%)$ \\
\hline Laboratory parameters & Median (IQR) \\
\hline Creatinine $(\mu \mathrm{mol} / \mathrm{l})$ & $95.5(74.0-123.8)$ \\
\hline GFR (ml/min) & $59.2(41.4-60.0)$ \\
\hline C-reactive protein $(\mathrm{mg} / \mathrm{l})$ & $4.9(2.0-11.1)$ \\
\hline $\mathrm{BNP}(\mathrm{pg} / \mathrm{ml})$ & $340.5(180.3-814.0)$ \\
\hline Hemoglobin (mmol/l) & $7.5(7.0-8.2)$ \\
\hline Hematokrit & $0.36(0.34-0.40)$ \\
\hline Troponin I (ng/ml) & $0.04(0.028-0.11)$ \\
\hline Creatinine kinase (U/l) & $1.25(0.98-1.94)$ \\
\hline Valve parameters & Total \\
\hline Transfemoral access & $77(83.7 \%)$ \\
\hline Transapical access & $15(16.3 \%)$ \\
\hline Edwards Sapien XT & $64(69.6 \%)$ \\
\hline Corevalve & $11(11.9 \%)$ \\
\hline JenaValve & $13(14.2 \%)$ \\
\hline SJM Portico & $4(4.3 \%)$ \\
\hline Valve size $(\mathrm{mm})$ & $26.3 \pm 2.24$ \\
\hline Complications & Total \\
\hline Stroke & $3(3.3 \%)$ \\
\hline TIA & $3(3.3 \%)$ \\
\hline \multicolumn{2}{|l|}{ Acute kidney injury } \\
\hline Stage 1 & $1(1.1 \%)$ \\
\hline Stage 2 & $1(1.1 \%)$ \\
\hline Stage 3 & $0(0.0 \%)$ \\
\hline Vascular comlications & Total \\
\hline Minor bleeding & $16(17.4 \%)$ \\
\hline
\end{tabular}

Table 1 continued

\begin{tabular}{lc}
\hline Vascular comlications & Total \\
\hline Major bleeding & $24(26.1 \%)$ \\
Life-threatening bleeding & $0(0.0 \%)$ \\
Access-related complications & $8(8.7 \%)$ \\
Patients requiring transfusions & $28(30.4 \%)$ \\
Mean number of tranfusions & 2.6 \\
New pacemaker requirement (72 h) & $5(5.4 \%)$ \\
New pacemaker requirement (7d) & $12(13.0 \%)$ \\
Conversion to open surgery & $1(1.1 \%)$ \\
Valve malpositioning & $1(1.1 \%)$ \\
Post-procedural aortic insufficiency & \\
None & $40(43.5 \%)$ \\
Grade 0-1 (trace) & $21(22.8 \%)$ \\
Grade 1 & $29(31.5 \%)$ \\
$\geq$ Grade 2 & $1(1.1 \%)$ \\
ICU treatment (h) & 26.0 \\
& $(23.0-47.8)$ \\
\hline
\end{tabular}

Interestingly, $\mathrm{CD} 31+/ \mathrm{CD} 42+\quad \mathrm{PMP}$ tended to increase over time after TAVI procedure. Base line concentration was $0.026 \%( \pm 0.0049 \% \mathrm{SD})$, after 1 week $0.024 \%( \pm 0.0038 \%$ SD $), 1$ month $0.052 \%( \pm 0.0080 \%$ $\mathrm{SD}, p=0.0003), 3$ months $0.060 \%( \pm 0.0101 \% \mathrm{SD}$, $p<0.0001)$ and 6 months $0.66 \%( \pm 0.0100 \%$ SD, $p<0.0001)$.

We also analyzed CD31+/Annexin+ and CD31+/ Annexin- EMP. Statistically significant differences were found neither for CD31+/Annexin+ nor CD31+/ Annexin- EMP. The basic mean level before TAVI for CD31+/Annexin+ EMP was $0.022 \%( \pm 0.0041 \% \mathrm{SD})$, after 1 week $0.021 \%( \pm 0.0043 \%$ SD), 1 month $0.022 \%$ $( \pm 0.0038 \%$ SD), 3 months $0.035 \%( \pm 0.0056 \%$ SD $)$ and after 6 months $0.031 \%( \pm 0.0049 \%$ SD). Similar results were found for CD31+/Annexin - EMP. Mean concentration before TAVI was $0.56 \%( \pm 0.048 \% \mathrm{SD})$, after 1 week $0.64 \%( \pm 0.047 \% \mathrm{SD}), 1$ month $0.68 \%( \pm 0.071 \% \mathrm{SD})$, 3 months $0.69 \%( \pm 0.086 \% \mathrm{SD})$ and after 6 months $0.63 \%( \pm 0.056 \% \mathrm{SD})$.

No differences were found between valve types or the approach that was used (transfemoral or transapical). Based on our clinical source data we have performed a comprehensive correlation analysis of EMP and PMP data points and correlated them to clinical features and also complications (using VARC-2 criteria) and valve types. Unfortunately and likely due to the small sample size in sub-groups we have not found any relevant correlations. When performing Bonferroni-Holm correction for multiple testing, no statistically significant correlations were found. 


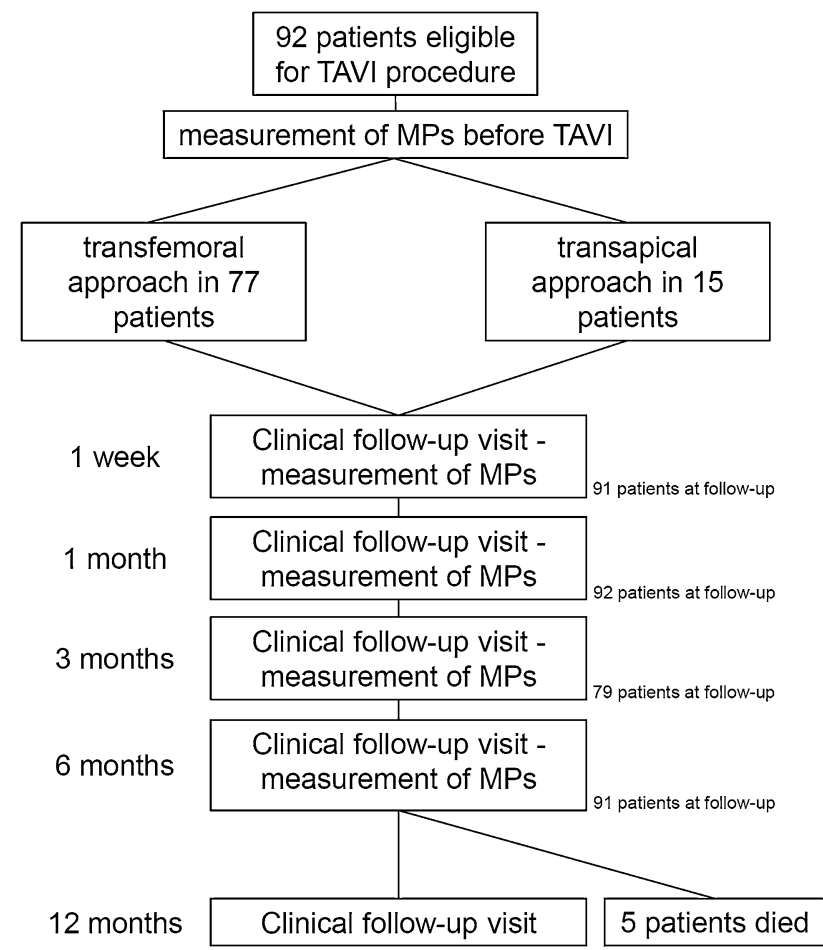

Fig. 1 Flow chart of the study protocol

\section{Discussion}

Previous studies have confirmed that elevated levels of microparticles are associated with progression of cardiovascular disease [29]. It was shown that high levels of CD62E + EMPs are associated with a worse outcome and higher rates of hospitalization in patients with stroke history [30]. Dehl et al. demonstrated in 2008 that EMP and PMP are elevated in the plasma of patients with severe aortic stenosis [31]. More recently, Horn et al. provided evidence that TAVI procedure reduces the number of circulating CD31+/CD42b- and CD62E+ EMP [25].

Here, in this study we sought to investigate the role of CD62E, CD31+/CD42b-, CD31+/Annexin+ and CD31+/Annexin- EMP and CD31+/CD42b + PMP in patients with severe aortic stenosis undergoing TAVI over a longer follow-up period of 6 months. Regarding functional parameters of aortic stenosis, we found a significant correlation of $\mathrm{CD} 31+/ \mathrm{CD} 41 \mathrm{~b}-$ but not CD62E + EMP with $V_{\max }$, MPG and PPG. Interestingly, no correlation was found for EMP levels with aortic valve area. This could be related to the fact the parameters for $V_{\max }$, MPG and PPG evidenced a greater statistical spread compared to AVA. Due the definition of aortic stenosis, AVA values are within a rather narrow range (between approximately 0.5 and $1.0 \mathrm{~cm}^{2}$ ). It is known that EMP are released upon shear stress from activated endothelial cells [20, 32]. In patients with severe aortic stenosis, vascular shear stress is constantly elevated leading to an increased expression of adhesion molecule expression [33, 34]. It was speculated that this pathophysiologic process could lead to further progression of valve calcification and dysfunction.

The main focus of our study was to evaluate whether TAVI procedure could lead to alteration or possible decrease in circulating levels of microparticles epitomizing an improvement in vascular integrity and function. We observed that after TAVI a significant decline in CD62E+ EMP occurs as evidenced at follow-up visits at 1, 3 and 6 months (Fig. 2a). Horn et al. already have verified that TAVI can reduce systemic levels of EMP. It was possible to corroborate these data in a larger cohort with a longer follow-up and show that CD62E + levels remained low over the whole follow-up period of 6 months. In contrast to the results by Horn et al., however, plasma concentration of CD31+/CD42b- EMP remained at baseline level at every visit after TAVI procedure (Fig. 2b).

Of special interest was the finding that PMP staining positive for $\mathrm{CD} 31+/ \mathrm{CD} 42 \mathrm{~b}+$ increased significantly over time after TAVI (Fig. 2c). In the study conducted by Horn et al. no changes in CD31+/CD42b+ PMP levels were recorded after TAVI procedure. In an experimental study by Franca et al. it was shown that PMP levels were not affected by the administration of clopidogrel over a surveillance period of 3 weeks [35]. We can only hypothesize that possible surface interaction effects of platelets and the newly implanted valve could have influenced the generation of PMP. In addition, CD31+/CD42b+ PMP levels might also be a surrogate parameter for beginning thrombus formation on cusps of the newly implanted valve [36, 37]. However, this remains truly speculative and further studies would be warranted to further elucidate the mechanism behind.

In the progression of cardiovascular disease and increased endothelial dysfunction and damage, apoptosis can be triggered leading to the release of CD31+/ Annexin+ EMP. The group of Sinning et al. demonstrated that heightened levels of CD31+/Annexin+ EMP are related to significantly increase cardiovascular mortality, need for revascularization and major adverse cardiovascular events [38]. In our study, levels of CD31+/Annexin + EMP did not evidence any differences during follow-up. One could speculate that TAVI leads to a halt in the progression of endothelial stress and dysfunction as CD31+/Annexin+ did not increase and CD62E+ EMP decreased over time. However, further prospective studies with longer follow-up are needed to provide evidence for this hypothesis.

As the shedding of microparticles is also associated with systemic inflammation and endothelial activation, a vicious circle of hemodynamic shear stress and endothelial dysfunction is present in the pathophysiological setting of AS. It was shown that inflammation might play a fundamental 
Table 2 Echocardiographic and laboratory parameter before TAVI and after 1 week and at 1, 3 and 6 months of follow-up

\begin{tabular}{llllll}
\hline & Pre TAVI & 1 week & 1 month & 3 months & 6 months \\
\hline Ejection fraction $(\%)$ & $55.9 \pm 18.4$ & $60.8 \pm 12.9^{*}$ & $58.4 \pm 16.3$ & $63.2 \pm 15.2^{* *}$ & $62.6 \pm 14.3^{* *}$ \\
$V_{\max }(\mathrm{m} / \mathrm{sec})$ & $4.34 \pm 0.7$ & $2.21 \pm 0.3^{* * *}$ & $2.22 \pm 0.5^{* * *}$ & $2.17 \pm 0.5^{* * *}$ & $2.23 \pm 0.6^{* * *}$ \\
Mean pressure gradient $(\mathrm{mmHg})$ & $46.5 \pm 14.8$ & $11.3 \pm 6.5^{* * *}$ & $11.1 \pm 5.4^{* * *}$ & $11.1 \pm 5.7^{* * *}$ & $11.6 \pm 6.1^{* * *}$ \\
Peak pressure gradient $(\mathrm{mmHg})$ & $77.5 \pm 22.7$ & $20.9 \pm 11.3^{* * *}$ & $20.7 \pm 10.8^{* * *}$ & $20.4 \pm 9.8^{* * *}$ & $21.2 \pm 11.1^{* * *}$ \\
Aortic valve area $\left(\mathrm{cm}^{2}\right)$ & $0.66 \pm 0.18$ & n.a. & n.a. & n.a. & n.a. \\
LVEDD $(\mathrm{mm})$ & $48.9 \pm 7.4$ & $49.8 \pm 7.3$ & $49.5 \pm 8.2$ & $47.9 \pm 6.9$ & $48.3 \pm 7.5$ \\
LVESD $(\mathrm{mm})$ & $31.7 \pm 9.4$ & n.a. & n.a. & n.a. & n.a. \\
Creatinin $(\mu \mathrm{mol} / \mathrm{l})$ & $95.5(74.0-123.8)$ & $81.5(67.5-118.8)$ & $93.0(75.0$ to \pm 128.0$)$ & $101.0(84.0-128.5)$ & $104.5(81.5-135.3)^{* *}$ \\
C-reactive protein $(\mathrm{mg} / \mathrm{l})$ & $4.8(2.0-11.1)$ & $37.4(20.0-59.6)^{* * *}$ & $4.9(2.2$ to 15.0$)$ & $3.4(2.0-7.9)$ & $3.1(2.0-5.9)$ \\
hemoglobin $(\mathrm{mmol} / \mathrm{l})$ & $7.5(7.0-8.2)$ & $6.6(6.2-7.2)^{* * *}$ & $7.3(6.6 \text { to } 8.0)^{* * *}$ & $7.6(6.9-8.5)$ & $7.9(7.2-8.5)$ \\
\hline
\end{tabular}

Significances are expressed vs. baseline parameters before TAVI

* Indicates a $p$ of $<0.05, * *$ a $p$ of $<0.01$ and $* * *$ a $\mathrm{p}$ of $<0.001$

n. $a$ data not available

Fig. 2 Correlation of CD $31+C D 42 b-$ EMP levels with parameters of aortic valve function. CD $31+C D 42 b-E M P$ evidenced a significant correlation with $V_{\max }$, MPG and PPG, however, no correlation was found with aortic valve area (AVA)
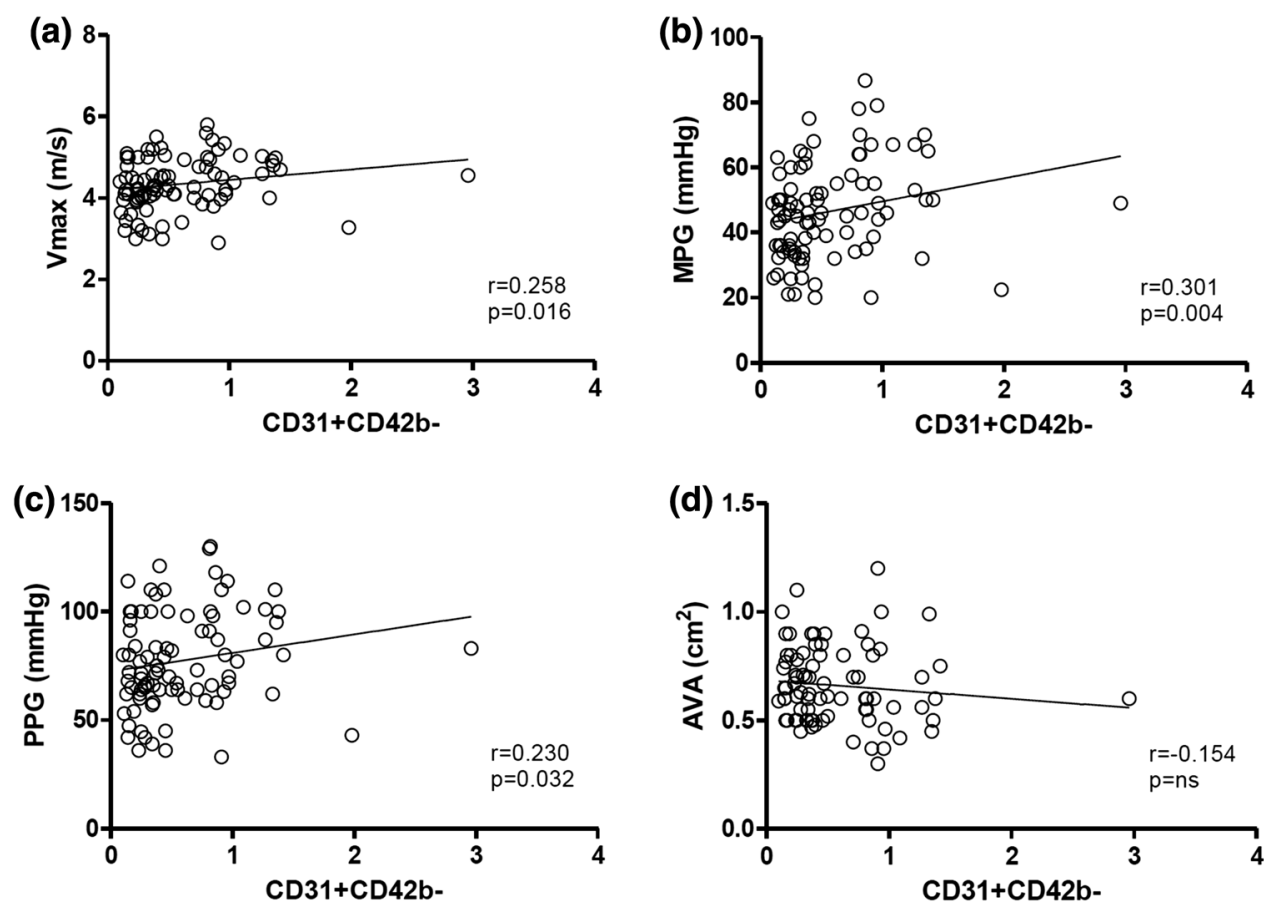

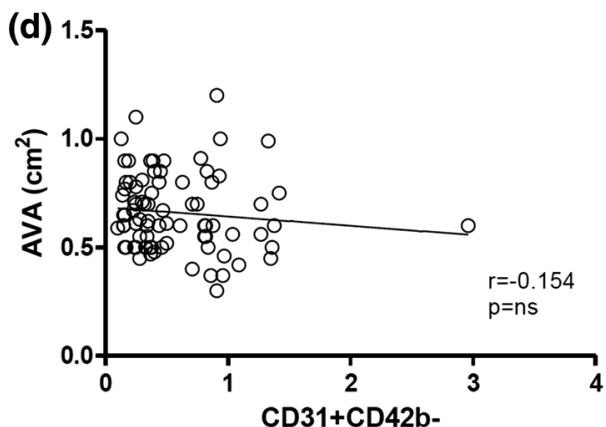

part in the progression of degenerative AS. Microparticles also seem to play a role as signaling factors within the vascular compartment mediating inflammatory, angiogenesis and coagulation $[39,40]$. TAVI proved to be a very promising procedure in considerably improving valvular function in patients with severe AS. As levels of CD62E + EMP were significantly reduced and other fractions of EMP did not increase during follow-up, one could argue that one factor for the progression of vascular dysfunction was taken out of the equation, thus leading to an improvement in endothelial function.

\section{Conclusion}

In conclusion, TAVI led not only to a procedure-related improvement in hemodynamic parameters, also endothelial dysfunction may have been alleviated by the procedure. 
Fig. 3 Levels of CD62E decreased significantly after TAVI procedure (a). CD $31+$ I CD42b- EMP concentrations did not change significantly after TAVI (b). CD31+/ CD42b+ PMP evidenced a significant increase during follow-up (c). Levels of CD31+/Annexin + and CD31+/Annexin- EMP were not altered after TAVI $(\mathbf{d}, \mathbf{e})$
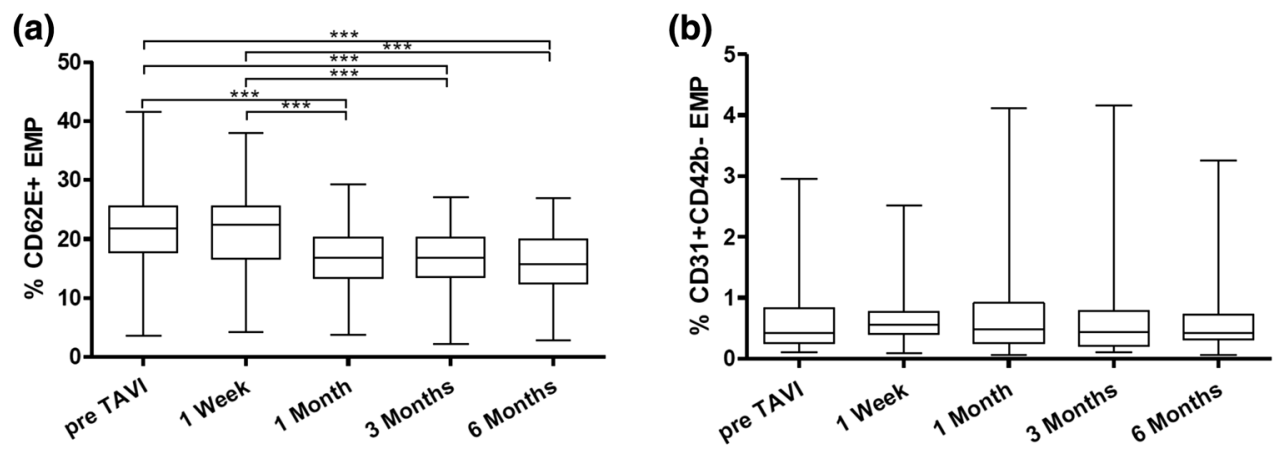

(c)

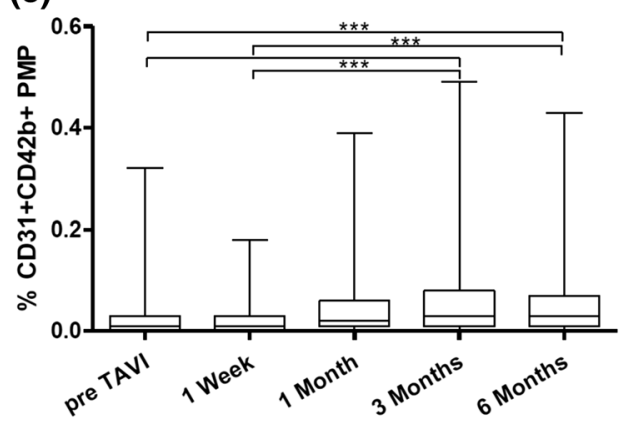

(d)

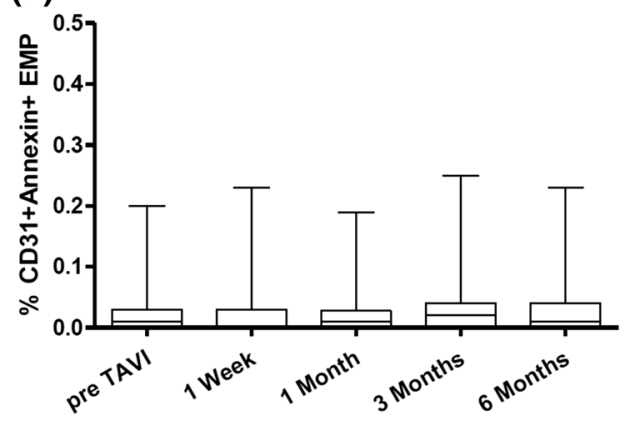

(e)

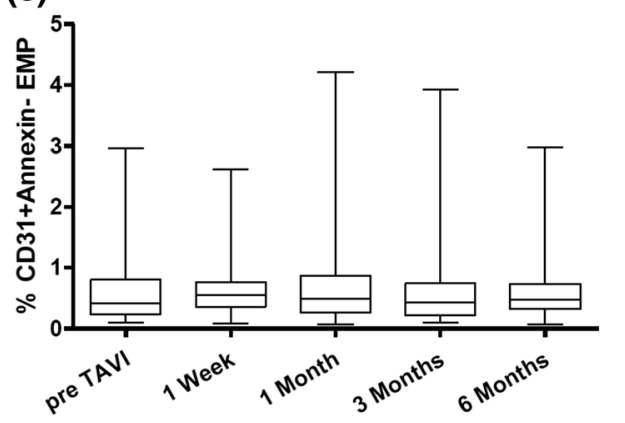

The reduction in transvalvular gradients and less hemodynamic shear stress seems also to have possible beneficial effects on endothelial homeostasis.

Acknowledgments Open access funding provided by Paracelsus Medical University. The authors thank Yvonne Schlenker and Annett Schmidt for their excellent technical assistance and Mrs. Kristen Kopp for proof-reading our manuscript.

\section{Compliance with ethical standards}

Conflict of interest The authors declare to have no conflict of interest. Funding was provided by the University Clinic Jena, Germany.

Open Access This article is distributed under the terms of the Creative Commons Attribution 4.0 International License (http://creativecommons.org/licenses/by/4.0/), which permits unrestricted use, distribution, and reproduction in any medium, provided you give appropriate credit to the original author(s) and the source, provide a link to the Creative Commons license, and indicate if changes were made.

\section{References}

1. Lindman BR, Bonow RO, Otto CM (2013) Current management of calcific aortic stenosis. Circ Res 113:223-237

2. Stolker JM, Patel AY, Lim MJ, Hauptman PJ (2013) Estimating the adoption of transcatheter aortic valve replacement by us interventional cardiologists and clinical trialists. Clin Cardiol 36:691-697

3. Nkomo VT, Gardin JM, Skelton TN, Gottdiener JS, Scott CG, Enriquez-Sarano M (2006) Burden of valvular heart diseases: a population-based study. Lancet 368:1005-1011

4. Horne A Jr, Reineck EA, Hasan RK, Resar JR, Chacko M (2014) Transcatheter aortic valve replacement: historical perspectives, current evidence, and future directions. Am Heart J 168:414-423

5. Galeone A, Paparella D, Colucci S, Grano M, Brunetti G (2013) The role of tnf-alpha and tnf superfamily members in the pathogenesis of calcific aortic valvular disease. ScientificWorldJournal 2013:875363

6. Yutzey KE, Demer LL, Body SC, Huggins GS, Towler DA, Giachelli CM, Hofmann-Bowman MA, Mortlock DP, Rogers MB, Sadeghi MM, Aikawa E (2014) Calcific aortic valve 
disease: a consensus summary from the alliance of investigators on calcific aortic valve disease. Arterioscler Thromb Vasc Biol 34:2387-2393

7. Kapadia SR, Yakoob K, Nader S, Thomas JD, Mann DL, Griffin BP (2000) Elevated circulating levels of serum tumor necrosis factor-alpha in patients with hemodynamically significant pressure and volume overload. J Am Coll Cardiol 36:208-212

8. Ferrari G, Sainger R, Beckmann E, Keller G, Yu PJ, Monti MC, Galloway AC, Weiss RL, Vernick W, Grau JB (2010) Validation of plasma biomarkers in degenerative calcific aortic stenosis. J Surg Res 163:12-17

9. Smith JG, Luk K, Schulz CA, Engert JC, Do R, Hindy G, Rukh G, Dufresne L, Almgren P, Owens DS, Harris TB, Peloso GM, Kerr KF, Wong Q, Smith AV, Budoff MJ, Rotter JI, Cupples LA, Rich S, Kathiresan S, Orho-Melander M, Gudnason V, O’Donnell CJ, Post WS, Thanassoulis G (2014) Association of low-density lipoprotein cholesterol-related genetic variants with aortic valve calcium and incident aortic stenosis. JAMA 312:1764-1771

10. Cappabianca G, Ferrarese S, Musazzi A, Terrieri F, Corazzari C, Matteucci M, Beghi C (2016) Predictive factors of long-term survival in the octogenarian undergoing surgical aortic valve replacement: 12-year single-centre follow-up. Heart Vessels. doi:10.1007/s00380-016-0804-3

11. Shim BJ, Lee DH, Youn HJ (2014) Increased soluble vascular adhesion molecule-1 concentration is associated with impaired coronary flow reserve in cardiac syndrome $x$. Heart Vessels 29:723-731

12. Lichtenauer M, Goebel B, Fritzenwanger M, Forster M, Betge S, Lauten A, Figulla HR, Jung C (2015) Simulated temporary hypoxia triggers the release of cd31+/annexin+ endothelial microparticles: a prospective pilot study in humans. Clin Hemorheol Microcirc 61:83-90

13. Jung C, Sorensson P, Saleh N, Arheden H, Ryden L, Pernow J (2012) Circulating endothelial and platelet derived microparticles reflect the size of myocardium at risk in patients with st-elevation myocardial infarction. Atherosclerosis 221:226-231

14. Montoro-Garcia S, Shantsila E, Wrigley BJ, Tapp LD, Abellan Aleman J, Lip GY (2015) Small-size microparticles as indicators of acute decompensated state in ischemic heart failure. Rev Esp Cardiol (Engl Ed) 68:951-958

15. Jung C, Rafnsson A, Shemyakin A, Bohm F, Pernow J (2010) Different subpopulations of endothelial progenitor cells and circulating apoptotic progenitor cells in patients with vascular disease and diabetes. Int J Cardiol 143:368-372

16. Jung C, Drummer K, Oelzner P, Figulla HR, Boettcher J, Franz M, Betge S, Foerster M, Wolf G, Pfeil A (2015) The association between endothelial microparticles and inflammation in patients with systemic sclerosis and raynaud's phenomenon as detected by functional imaging. Clin Hemorheol Microcirc 61(3):549-557

17. Satta N, Toti F, Feugeas O, Bohbot A, Dachary-Prigent J, Eschwege V, Hedman H, Freyssinet JM (1994) Monocyte vesiculation is a possible mechanism for dissemination of membraneassociated procoagulant activities and adhesion molecules after stimulation by lipopolysaccharide. J Immunol 153:3245-3255

18. Combes V, Simon AC, Grau GE, Arnoux D, Camoin L, Sabatier F, Mutin M, Sanmarco M, Sampol J, Dignat-George F (1999) In vitro generation of endothelial microparticles and possible prothrombotic activity in patients with lupus anticoagulant. $\mathrm{J}$ Clin Invest 104:93-102

19. Jung C, Lichtenauer M, Wernly B, Franz M, Goebel B, Rafnsson A, Figulla HR, Pernow J (2016) Effect of endothelin-1 and endothelin receptor blockade on the release of microparticles. Eur J Clin Invest 46(8):707-713. doi:10.1111/eci.12652
20. Chironi GN, Boulanger CM, Simon A, Dignat-George F, Freyssinet JM, Tedgui A (2009) Endothelial microparticles in diseases. Cell Tissue Res 335:143-151

21. Feng B, Chen Y, Luo Y, Chen M, Li X, Ni Y (2010) Circulating level of microparticles and their correlation with arterial elasticity and endothelium-dependent dilation in patients with type 2 diabetes mellitus. Atherosclerosis 208:264-269

22. Koga H, Sugiyama S, Kugiyama K, Watanabe K, Fukushima H, Tanaka T, Sakamoto T, Yoshimura M, Jinnouchi H, Ogawa H (2005) Elevated levels of ve-cadherin-positive endothelial microparticles in patients with type 2 diabetes mellitus and coronary artery disease. J Am Coll Cardiol 45:1622-1630

23. Abrams CS, Ellison N, Budzynski AZ, Shattil SJ (1990) Direct detection of activated platelets and platelet-derived microparticles in humans. Blood 75:128-138

24. Bal L, Ederhy S, Di Angelantonio E, Toti F, Zobairi F, Dufaitre G, Meuleman C, Mallat Z, Boccara F, Tedgui A, Freyssinet JM, Cohen A (2010) Factors influencing the level of circulating procoagulant microparticles in acute pulmonary embolism. Arch Cardiovasc Dis 103:394-403

25. Horn P, Stern D, Veulemans V, Heiss C, Zeus T, Merx MW, Kelm M, Westenfeld R (2015) Improved endothelial function and decreased levels of endothelium-derived microparticles after transcatheter aortic valve implantation. EuroIntervention 10:1456-1463

26. Pirro M, Schillaci G, Paltriccia R, Bagaglia F, Menecali C, Mannarino MR, Capanni M, Velardi A, Mannarino E (2006) Increased ratio of $\mathrm{cd} 31+/ \mathrm{cd} 42-$ microparticles to endothelial progenitors as a novel marker of atherosclerosis in hypercholesterolemia. Arterioscler Thromb Vasc Biol 26:2530-2535

27. Kappetein AP, Head SJ, Genereux P, Piazza N, van Mieghem NM, Blackstone EH, Brott TG, Cohen DJ, Cutlip DE, van Es GA, Hahn RT, Kirtane AJ, Krucoff MW, Kodali S, Mack MJ, Mehran R, Rodes-Cabau J, Vranckx P, Webb JG, Windecker S, Serruys PW, Leon MB (2012) Updated standardized endpoint definitions for transcatheter aortic valve implantation: the valve academic research consortium-2 consensus document. Eur Heart J 33:2403-2418

28. Biancari F, Barbanti M, Santarpino G, Deste W, Tamburino C, Gulino S, Imme S, Di Simone E, Todaro D, Pollari F, Fischlein T, Kasama K, Meuris B, Dalen M, Sartipy U, Svenarud P, Lahtinen J, Heikkinen J, Juvonen T, Gatti G, Pappalardo A, Mignosa C, Rubino AS (2016) Immediate outcome after sutureless versus transcatheter aortic valve replacement. Heart Vessels 31:427-433

29. Shantsila E, Kamphuisen PW, Lip GY (2010) Circulating microparticles in cardiovascular disease: implications for atherogenesis and atherothrombosis. J Thromb Haemost 8:2358-2368

30. Lee ST, Chu K, Jung KH, Kim JM, Moon HJ, Bahn JJ, Im WS, Sunwoo J, Moon J, Kim M, Lee SK, Roh JK (2012) Circulating cd62e+ microparticles and cardiovascular outcomes. PLoS One 7:e35713

31. Diehl P, Nagy F, Sossong V, Helbing T, Beyersdorf F, Olschewski M, Bode C, Moser M (2008) Increased levels of circulating microparticles in patients with severe aortic valve stenosis. Thromb Haemost 99:711-719

32. Vion AC, Ramkhelawon B, Loyer X, Chironi G, Devue C, Loirand G, Tedgui A, Lehoux S, Boulanger CM (2013) Shear stress regulates endothelial microparticle release. Circ Res 112:1323-1333

33. Dabagh M, Vasava P, Jalali P (2015) Effects of severity and location of stenosis on the hemodynamics in human aorta and its branches. Med Biol Eng Comput 53:463-476

34. Rouleau L, Copland IB, Tardif JC, Mongrain R, Leask RL (2010) Neutrophil adhesion on endothelial cells in a novel asymmetric stenosis model: effect of wall shear stress gradients. Ann Biomed Eng 38:2791-2804 
35. Franca CN, Pinheiro LF, Izar MC, Brunialti MK, Salomao R, Bianco HT, Kasmas SH, Barbosa SP, de Nucci G, Fonseca FA (2012) Endothelial progenitor cell mobilization and platelet microparticle release are influenced by clopidogrel plasma levels in stable coronary artery disease. Circ J 76:729-736

36. Makkar RR, Fontana G, Jilaihawi H, Chakravarty T, Kofoed KF, de Backer O, Asch FM, Ruiz CE, Olsen NT, Trento A, Friedman J, Berman D, Cheng W, Kashif M, Jelnin V, Kliger CA, Guo H, Pichard AD, Weissman NJ, Kapadia S, Manasse E, Bhatt DL, Leon MB, Sondergaard L (2015) Possible subclinical leaflet thrombosis in bioprosthetic aortic valves. N Engl J Med 373:2015-2024

37. Pache G, Schoechlin S, Blanke P, Dorfs S, Jander N, Arepalli CD, Gick M, Buettner HJ, Leipsic J, Langer M, Neumann FJ, Ruile P (2015) Early hypo-attenuated leaflet thickening in balloon-expandable transcatheter aortic heart valves. Eur Heart J. doi:10.1093/eurheartj/ehv526

38. Sinning JM, Losch J, Walenta K, Bohm M, Nickenig G, Werner $\mathrm{N}$ (2011) Circulating cd31+/annexin v+ microparticles correlate with cardiovascular outcomes. Eur Heart J 32:2034-2041

39. Gwechenberger M, Hulsmann M, Berger R, Graf S, Springer C, Stanek B, Pacher R (2004) Interleukin-6 and b-type natriuretic peptide are independent predictors for worsening of heart failure in patients with progressive congestive heart failure. J Heart Lung Transplant 23:839-844

40. Gwechenberger M, Mendoza LH, Youker KA, Frangogiannis NG, Smith CW, Michael LH, Entman ML (1999) Cardiac myocytes produce interleukin- 6 in culture and in viable border zone of reperfused infarctions. Circulation 99:546-551 